\title{
Building blocks: a strategy for near-term action within the new global climate framework
}

\author{
Richard B. Stewart ${ }^{1}$ - Michael Oppenheimer ${ }^{2}$. \\ Bryce Rudyk ${ }^{1}$ (D)
}

Received: 29 August 2016 / Accepted: 19 February 2017 / Published online: 10 March 2017

(C) The Author(s) 2017. This article is published with open access at Springerlink.com

\begin{abstract}
The Paris Agreement cemented a new framework for global climate policy based on the voluntary and non-legally binding emission reduction actions by both developed and developing countries. The building blocks strategy for climate action discussed in this Special Issue is well adapted to and strongly complements this new structure. Building blocks focus on multiple transnational mechanisms for mobilizing a wide range of both public and private actors to take actions that reduce emissions by capturing incentives other than climate mitigation as such. The initial commitments by countries under the Paris Agreement are insufficient to meet the level of action required to stabilize the global climate system at a safe level. As such, new voluntary action by public and private actors will be required. The building blocks strategy, and the examples presented in this Special Issue, offers answers to the question of how to generate and design smaller-scale initiatives.
\end{abstract}

The Paris Agreement cemented an entirely new framework for the global climate regime, one based on countries' voluntary emissions limitation plans (nationally determined contributions or NDCs) and which includes participation by both developing and developed countries on a continuum of mitigation capability rather than a dichotomy. The previous framework, embodied in the principles of the UNFCCC and the Kyoto Protocol, aimed for universal agreement on economy-wide, binding, top-down quantitative targets and timetables for developed countries while excepting developing countries. Given the inherent difficulties in reaching international agreement under this approach (Stewart et al. 2013a), decomposition of climate policy into smaller problem-solving components was proposed as a crucial step toward effective global cooperation (Aldy and Stavins 2007; Victor 2011).

This article is the introduction to a Special Issue on "Alternate Structures for Global Climate Action: Building Blocks Revisited" edited by Richard B. Stewart and Bryce Rudyk.

Bryce Rudyk

bryce.rudyk@nyu.edu

1 New York University, New York, NY, USA

2 Woodrow Wilson School and Department of Geosciences, Princeton University, Princeton, NJ, USA 
Despite the Paris Agreement being potentially the best agreement which could have been reached under the circumstances (Bodansky 2016), it is insufficiently ambitious to limit the global mean temperature increase to $2{ }^{\circ} \mathrm{C}$ (UNFCCC 2015) - additional climate action will be required. As the NDCs were supposedly the maximum that countries were able or willing to do individually, any additional action over the same period will be taken primarily by non-state actors or countries acting cooperatively in other contexts. And although there has been increased climate action by non-state actors, this has not happened at a convincing scale in the context of a $2{ }^{\circ} \mathrm{C}$ objective.

While the concept of bottom-up action on climate is not novel-it was much discussed during the lull in the international negotiations and international climate action in advance of Copenhagen (Aldy and Stavins 2007) - the Paris Agreement is novel in that it brings disaggregated bottom-up action into an international framework. Some climate negotiators have suggested that a focus on non-state actors will reduce the pressure on countries to fulfill their NDCs and to make more ambitious commitments in the future. Therefore, to be most effective, the additional action should seek to strengthen the international regime created in Paris.

This Special Issue is focused on how to incentivize this additional climate action through a building blocks strategy and to do so in a way that enhances the Paris Agreement. The building blocks strategy is a bottom-up strategy designed to create an array of smaller-scale, specialized initiatives for transnational cooperation in particular sectors and/or geographic areas with a wide range of participants - private sector, NGOs, international organizations, and subnational and local governments, as well as national governments. Key to the building blocks initiatives are a focus on the non-climate incentives of actions that also have a climate benefit. Such incentives include private economic benefits, reduction of local and regional air pollution, economic development and energy security for countries, and mission advancement for development funders.

The building blocks strategy provides not only a theory of action but also a template for designing these initiatives and offers suggestions on how to generate momentum to develop these initiatives. It can strengthen the Paris Agreement in three ways: (1) by providing additional climate action by state and non-state actors in the short term; (2) by understanding opportunities and costs of increased action, it can help countries to increase the ambition in subsequent NDCs; and (3) by developing transparency and monitoring systems in building blocks initiatives, they may provide best practices and examples for the development of similar systems under the Paris Agreement, which are currently thinly defined (Bodansky 2016).

In this introduction to the Special Issue, we first provide a summary of the theory of building blocks that we have developed in greater detail in several earlier publications (Stewart et al. 2013a, b, 2015). We articulate the specific institutional logics of the building blocks strategy — clubs, institutional linkages, and dominant market actors-providing examples of initiatives that follow these logics. As well, we introduce the other papers of the Special Issue, noting how they complement and extend the building blocks proposal. Finally, we discuss how the building blocks can enhance the Paris Agreement and how the Paris Agreement can, in turn, enhance the development and stability of building blocks initiatives.

\section{The building blocks conception and institutional paradigms}

The core elements of the building blocks conception are as follows:

1. Enlist a limited number of public and/or private actors.

2. Focus on sectors and opportunities with high mitigation potential. 
3. Tap actor incentives other than a desire to promote climate mitigation.

4. Establish special-purposed initiatives that mobilize such incentives to generate transnational cooperative activities that reduce GHG emissions.

5. The arrangements need not be legally binding or formally linked to the UNFCCC.

The building blocks approach deploys three institutional logics for operationalizing this conception.

Club strategy This strategy involves limited membership transnational regimes that produce economic or other non-climate benefits exclusively or primarily for participants through cooperative activities that also reduce emissions. These targeted non-climate benefits may include reduced energy costs, energy security, profitable R\&D innovations, and competitive advantage including through first-mover advantages and reputational benefits. Participants include states, international organizations, and the private sector, and the non-climate benefits only accrue to those that actively participate in the club.

Linkage strategy This strategy leverages existing transnational organizations with missions other than climate protection. By tapping strategically situated actors or members with the organization that support mitigation, initiatives can be launched that further the organization's basic mission while also achieving emission reductions. Examples are rural renewable energy and low-GHG agriculture in bilateral and multilateral development programs and increasing the purview of the Montreal Protocol to include currently unregulated ozone-depleting substances (ODS; Ovodenko 2016) or ODS substitutes that are also GHGs.

Dominant market actor strategy The third strategy reduces emissions through the power of governmental authorities or business firms with a dominant economic position in specific global or regional market sectors that enables them to effectively determine or strongly influence the regulatory norms governing the sector. The dominant actor may or may not have climate protection objectives; firms in the sector must comply in order to comply with law and remain competitive. In another model, single or small groups of actors may simply exercise market power to determine a technological direction favorable to emission reduction.

The building blocks strategies, which mobilize different types of incentives through different institutional structures, avoid many of the problems experienced in achieving a binding comprehensive international agreement on emissions limitations.

First, experience shows that it is often easier to reach agreement among a smaller number of participants on substantive goals as well as critically important institutional and procedural issues such as monitoring and other arrangements to ensure compliance (Carin and Mehlenbacher 2010). The building blocks initiatives are not designed either to be comprehensive in scope or inclusive of all actors. In Geoffrey Heal and Howard Kunreuther's article in this Special issue, they focus on the development of a tipping set of countries within the international climate negotiations. They argue that with a limited set of actors with strategic power, policy choices by the set can raise the net return of all other actors which make the same policy choices and therefore make the selection of the policy choice more likely. They suggest that 2014 US-China joint announcement on climate change could be a tipping set on the road to the Paris Agreement (Heal and Kunreuther 2017).

Second, the incentive to reduce emissions varies widely across countries and is rarely an incentive for non-state actors. An inclusive comprehensive regime cannot be built on the 
intense support in some jurisdictions and the lack of interest or hostility in others, without tremendous side payments (Barrett 2003). The building blocks strategy adapts to this challenge by mobilizing incentives that matter to a range of actors, such as economic gains, increased adaptation capacity and health, economic development, energy security, and other benefits. The regimes would, however, be designed so as to produce emissions reductions as a side or supplemental benefit of cooperation. The strategy also draws on existing pockets of support for mitigation, including in governments unwilling to commit to economy-wide emissions caps but willing to participate in more limited undertakings.

Third, as in any regime, there must be methods to monitor participants' adherence to the rules of the regime and exclude them from the benefits, where necessary. The varied nature of the building blocks initiatives allows for experimentation in monitoring and compliance arrangements. Few building blocks initiatives will require, or have the capacity for, strict trade sanctions like those we find in the Montreal Protocol or World Trade Organization. Some may ensure compliance through exclusion from club benefits, financing access, or market access, but many others will require monitoring and compliance regimes that are softer. In Joseph Aldy's paper in this Special Issue, he focuses on the concept of policy surveillance as a tool for monitoring and compliance (Aldy 2017). He uses the example of the 2009 G20 Fossil Fuel Subsidies Agreement, in which participants pledged to pursue the same policy objective, created implementation plans subject to peer review, and then had their performance subject to review by international independent experts. While this form of policy surveillance may not be appropriate for the Paris Agreement as a whole, it may be useful in particular types of building blocks initiatives.

Fourth, the benefits of building blocks initiatives extend beyond the immediate emissions reductions that they achieve. In the climate negotiations, it is often argued that due to the uncertainty in the costs of climate action, countries should be conservative in their commitments. Unlocking greater action could be achieved through a better understanding of the costs of action. In Charles Sabel and David Victor's article in this Special Issue, he argues that given the smaller size and lower cost of failure of building blocks initiatives, they can lead to significant learning about the costs of mitigation action and institutional experimentation that could elucidate the characteristics of durable initiatives (Sabel and Victor 2017). This could lead leading to additional, and more effective, future initiatives.

In addition to greater information, building blocks initiatives can also promote increased trust through demonstrating action for transnational cooperation and creating institutions that regularize interactions between public and private actors. Initiatives that stimulate subnational activities with climate co-benefits can mobilize domestic actors to promote adoption of such measures by their national governments. In these various ways, discrete building blocks initiatives can lay a basis for greater long-term ambition.

The building blocks strategy advances beyond general calls for bottom-up initiatives and transnational collaboration by providing specific institutional paradigms for engaging actors in transnational cooperative activities that reduce emissions. The club, linkage, and dominant actor paradigms provide a systemic framework for policy entrepreneurs to assess potential initiatives and analyze the incentives and actors that would be required to mobilize each initiative.

\subsection{Clubs}

Since our earlier papers on the use of clubs for climate (Stewart et al. 2013a, b, 2015), there has been much discussion of a range of plurilateral cooperative mechanisms to achieve emission 
reductions (Weischer et al. 2012; Sabel and Victor 2017; Nordhaus 2015a, b; Falkner 2016). Some of these arrangements - often referred to as "clubs" - stray far from the classic economic model of club goods: the provision to members of excludable, non-rival goods through essentially contractual institutional arrangements (Buchanan 1965). Many "club" proposals are not rigorous about the participants' incentives and quite often rely on climate altruism - a non-excludable public good that may be robust and durable for only a very limited number of public and private actors. What matters, however, is not the label but clarity that only a certain incentives set can keep actors in an arrangement that does not require external enforcement (Green 2017). The type and strength of the incentives (club good benefits) will determine the type and strength of obligations that can be imposed on the members by the arrangement and the climate co-benefits generated. We propose a continuum of club-like arrangements that run from classic economic clubs to pseudo-clubs, to coalitions, which are much looser forms of cooperation, such as $\mathrm{C} 40$, to share information and advance a common agenda. Along the continuum, the benefits to the members become less excludable and the incentives weaker, although some free riding on benefits may occur even in classic clubs. In Philip Hannam, Vitor Vasconcelos, Simon Levin, and Jorge Pacheco's paper in this Special Issue, the authors produce a model that challenges the traditional understanding that goods must be fully excludable in order for clubs to be viable. Through examples from a variety of different regimes, they show that sustained cooperation on public goods is possible even where the good is not fully excludable and where there is free riding.

\subsubsection{Classic clubs}

These are arrangements, usually of a limited number of actors, which produce a tangible good (e.g., new technology, pooled finance, pooled risk, and common standards) that confers excludable economic or other non-climate benefits such as reduced energy costs, energy security, or profitable R\&D innovations. Defection from the club is managed by limiting club benefits to members who abide by its rules. If the benefits of membership are greater than the costs, then the club is essentially self-enforcing - no rational actor is likely to exit the club barring a fundamental change in circumstances. Monitoring arrangements are needed to ensure that all members abide by the club bargain.

In their article for the Special Issue, Nathaniel Keohane, Annie Petsonk, and Alex Hanafi propose a "club of carbon markets" that would link carbon markets from jurisdictions that met minimum eligibility criteria (e.g., emissions targets, domestic legislation covering compliance and penalties, and commitment to transparent monitoring). They argue that the incentives to link are significant, including the economic benefits of a broader pool of emissions credits, institutional sharing for transparency and monitoring, potential safe harbor on trade challenges, and reputational benefits (Keohane et al. 2017). The club would provide an excludable benefit by limiting trading with those outside the club and exclusion from trading for non-compliance.

Another example is an industry club for technology research, development, and deployment. Club members pay dues in terms of finance, research collaboration, or patent sharing. The benefit is the joint development of technology and the resulting risk pooling and economic benefits that result from the commercialization of the technology. For example, the Canada's Oil Stands Innovation Alliance is an industry club in which environmentally beneficial technologies developed by any of the members of the Alliance are shared royalty-free to the other members (Krugel 2013). Another potential example is the current initiative by a group of 
countries, proceeding under the umbrella of the WTO, to reach agreement on tariff reductions for green goods (WTO 2016). Such an agreement, to the extent that the tariff reductions were exclusive, would be considered a classic club. However, if there was not a reciprocal requirement for reductions, then a green goods club would best be considered a pseudo-club.

The incentives for participation in clubs need not be uniform for all members (Hannam et al 2017). Businesses or some developing countries may join an arrangement in order to receive economic benefits or other club goods limited to members, while other states and subnational jurisdictions may join and support the club activities in order to secure emissions reductions, a global public good. For example, we could imagine clubs to deploy renewable energy on small islands in which developed countries provide finance to achieve mitigation, technology companies provide installations and services to earn profits, and developing countries provide infrastructure support which results in energy, economic, and other local benefits.

\subsubsection{Pseudo-clubs}

These arrangements are reliant on benefits that are more diffuse, less readily excludable, and potentially less easily quantifiable. The club goods may be reputational benefits from adopting standards or labels or the opportunity to influence future public or private regulation and gain first-mover benefits. Despite these softer club goods, they may be sufficient to sustain this form of club, but not if it produces significant costs for parties. Jessica Green, in her article in this Special Issue, uses the example of carbon measurement and disclosure clubs to argue that despite their limited benefits and excludability, these low-barrier-to-entry pseudo-clubs can have utility in coordinating actors to solve technical issues. These pseudo-clubs could attract broad membership, which could be helpful in propagating standards, but she finds that absent greater incentive (i.e., government regulation), these pseudo-clubs will not move from monitoring to regulating emissions.

Like traditional clubs, monitoring arrangements will be important to ensure that noncompliance with the rules is minimized. Additionally, institutional arrangements that increase the reputational benefits by increased publicity of pseudo-club actions, or expand the firstmover benefits by lobbying for adoption of standards, may help to make pseudo-clubs more durable.

Pseudo-clubs generally exploit two sets of non-mutually exclusive incentives: first-mover and reputational benefits. We often see first-mover benefits in situations that involve standard setting, as in the multi-stakeholder Greenhouse Gas Protocol, which sets emission measurement standards (Green 2017). The incentive to the initial actors is the ability to shape the developing standard to their benefit. Public and private actors may then use the standards for various reasons - reputation, demands of investors or supply chain counterparts, influencing the development of governmental regulatory standards, possible future regulatory credits, and so on. In these circumstances, the benefits that accrue to the participants may be time-limited. Once the standard has been propagated, the first-mover benefits may be diluted.

In his paper in this Special Issue, Matthew Potoski examines the second type of incentive - reputation - with the example of green certification clubs. He argues that these types of pseudo-clubs are attractive to private actors because they create a value that the actors cannot create themselves, namely, the reputational benefit for being associated with an independent certification regime (Potoski 2017). The strength of the reputational benefit will depend on the perception and prevalence of the label and, in some cases, sponsorship by prominent nongovernmental organizations. 


\subsubsection{Coalitions}

These arrangements have no excludable club benefit, generally do not require significant commitments from their members, and the corresponding benefits of information sharing, discussions fora, and publicity may be similarly small. Unlike clubs and pseudo-clubs, coalitions generally do not set standards that participants must follow, hence no arrangements for monitoring compliance. Rather, minimal institutional arrangements to share information or convene actors will be required.

Many of the arrangements that have been referred at climate negotiations and related events as clubs are actually coalitions. For example, the C40, the group of global mayors and cities acting on climate change, is primarily a coalition for information sharing and discussion. No standards are established or commitments required from participants.

Establishing and building successful clubs, pseudo-clubs, or coalitions involves a number of challenges. The first is who will have the incentive to incur the costs of start-up organization; this may be limited to dominant firms industry, public bodies, or large NGOs. These startup costs may be significant as clubs must develop governance arrangements for decisionmaking among participants, work out the terms of cooperation, and monitor member performance with varying stringency. Second, they must deploy effective exclusionary mechanisms to limit club benefits to members and punish shirking by members, or be satisfied with lesser incentives and corresponding benefits. These mechanisms may include arrangements that only allow members' access to patented technologies or know-how or preferential trade rules for members. ${ }^{1}$ Without such arrangements, clubs will fail for the same reasons that plague cooperation to provide public goods.

\subsection{Linkage}

This strategy leverages existing transnational organizations with primary missions other than climate protection. In some cases, strategically situated organizational actors that support mitigation may instigate initiatives that further the organization's basic mission or are coherent with it while also achieving emissions reductions. Such an approach harnesses the organization's capacities, machinery, and established norms for implementing its non-climate objectives in order to simultaneously advance climate protection.

In the past year, there have been two significant cases in which political pressure by members of organizations has resulted in new initiatives directed at climate protection. First, the Montreal Protocol (MP), on the initiative of the USA and the EU, agreed to regulate hydrofluorocarbons, a class of potent greenhouse gases (Ovodenko 2016). While these are not ozone-depleting substances, their production was a direct result of the Protocol's constraints on ozone-depleting halocarbons. Utilizing the MP was attractive because of its powerful set of participation and compliance provisions, involving side payments from the Multilateral Fund,

\footnotetext{
${ }^{1}$ The creation of clubs, and the potential of having preferential trade rules among club members, may potentially be contrary to WTO rules. It is not clear whether the exception concerning regional trade agreements may be used for thematic, regionally based clubs. However, it is beyond the scope of this paper to consider the trade issues. For a preliminary discussion of the trade law issues surrounding this type of response, see Patrick Low, Gabrielle Marceau, and Julia Reinaud, The Interface Between the Trade and Climate Change Regimes: Scoping the Issues 6 (World Trade Org., Working Paper No. ERSD-2011-1, 2011). Available at http://www.wto.org/english/res e/reser_e/ersd201101_e.pdf.
} 
substantial technical assistance for technological transitions, and the potential of trade sanctions. The second example is the development of the Carbon Offsetting and Reduction Scheme for International Aviation under the International Civil Aviation Authority (ICAO), under pressure from domestic regulation on aviation emissions in the EU (Green 2016). Again, the inclusion of this initiative within ICAO leverages the organization's institutional framework for implementation, monitoring, and compliance.

As well, there has been increasing climate action linked to development finance. The missions of multilateral development banks have already to a certain extent been redirected away from investment in fossil fuel power projects and toward alternatives. Similarly, the USA, acting to reinforce its own priorities, negotiated a commitment from China to alter its large-scale support for coal projects in Asia, for example by changing its criteria for lending via the Asian Infrastructure Investment Bank, South-South Cooperation Fund, and other such institutions (Hannam et al 2017). Existing institutionalized patterns of cooperation among an institution's members can be mobilized to support non-climate initiatives that not only selectively benefit the members but also reduce GHGs. An example is the ASEAN Agreement on Transboundary Haze Pollution, which could be amended to include an initiative to reduce not only pollutants that are causing regional haze but also GHGs (Tacconi 2016).

\subsection{Dominant market actors}

The third strategy attempts to reduce GHG emissions though the power of government regulators or firms acting from a dominant position in specific global or regional market sectors. Their dominant position enables them effectively to determine or strongly influence the standards governing the sector. When this occurs in a sufficiently large market, scale economy and other considerations may induce producers to follow the standards in producing for other markets as well. This phenomenon has been analyzed as the California effect (California motor vehicle emission standards) or the Brussels effect (EU product regulations; Bradford 2013). Where dominant public or private actors envisage sufficient economic, strategic, or other gains from acting as first movers with regulatory or market standards, they may act unilaterally with the goal of inducing others in a sector to follow suit. In some cases, dominant firms' influence would be exercised in conjunction with, in anticipation of, or in order to stimulate supportive government regulatory measures. Dominant public and private actors may effectively collaborate. Cause and effect is not easily separable, as in the example of synergy between DuPont's interests in alternatives to ozone-depleting chemicals and the US government's support for a strong Montreal Protocol (Benedick 1998); what matters from our perspective are contexts where such intentional or fortuitous collaboration is feasible.

A dominant private firm or small group of firms in a market for a given climate-beneficial technology, such as wind turbine nacelles or grid technologies, may adopt or promote adoption by governmental authorities of a product or performance standard that will give it a competitive advantage but also secure greenhouse gas reductions. Government regulators may leverage market power to advance climate protection as such. An example of the latter is the extension of the EU's emission trading system for regulating domestic emissions to international airlines serving the European market, which then drove action at ICAO. Similarly, dominant shipping firms like Maersk and China Navigation are pressuring the International Maritime Organisation, and its member states, to develop climate mitigation policies for shipping, the largest economic sector not subject to international climate regulation (Vidal 2016). 
Emerging renewable energy markets provide another example. Germany's Renewable Energy Sources Act of 2000 created a large new market for solar, wind, and bioenergy technologies. At roughly the same time and perhaps in response, China made a large bet on marketing solar and wind technologies, increasing the production of photovoltaic panels by more than 100-fold since 2005 (Wagner et al 2015). Each country exercised immense market power on the demand and supply sides, respectively, and as a result had a strong and perhaps revolutionary influence on the price and quantity of renewables. Whether the actions in this case were intentional or largely serendipitous, future opportunities for fostering such initiatives should be encouraged, recognized, and exploited.

While in theory a dominant firm or group of firms might already have taken action if they would thereby benefit, the key element in many contexts is the availability or not of governmental action that helps change or reinforce the incentives. More broadly, the rational expectations model gives an imperfect account in such dynamic situations. A role exists for public and private policy entrepreneurs attentive to evolving market conditions and public sector preferences.

\section{Interaction between building blocks and the UNFCCC: providing benefits to both}

As the building blocks are driven by non-climate incentives, they can continue to be developed and deployed notwithstanding the UNFCCC and the international climate architecture. Similarly, as the primary intergovernmental response to climate change, the UNFCCC can continue to operate as a states-only club focused on the climate actions of the national government parties to the Paris Agreement. But the reality is that the Paris Agreement is insufficiently ambitious to meet its long-term temperature target, and the voluntary building blocks initiatives are not yet being created at scale.

There are already significant interactions between these two complimentary forms of global climate action. National governments are participating in, and indeed creating, building blocks initiatives, and the UNFCCC has for a few years been developing a new action agenda to engage actors beyond states.

\subsection{Building blocks enhancing the political viability and effectiveness of the Paris Agreement}

The building blocks strategy can help strengthen the Paris Agreement in a number of ways. First, the emissions reductions contained in the NDCs are inadequate to meet the long-term temperature targets of the Paris Agreement. If this emissions gap between needed action and actual action continues, it undermines the effectiveness and political viability of the Paris Agreement. In helping to create additional near-term emissions reductions, it is likely that the deployment of building blocks initiatives can help strengthen the evolving Paris Agreement.

Second, they can help increase ambition in subsequent NDCs. Many existing NDCs are highly general in character, containing aggregate emissions reduction targets but little detail on specific measures to achieve reductions. To be most effective, the future NDCs should describe the specific regulatory and policy initiatives to reduce emissions and, where appropriate, descriptions of the support necessary to achieve these reductions. 
Third, the plurilateral, multi-actor nature of building blocks initiatives allows diverse agents to pool resources and knowledge, experiment with different measures, track performance, and identify and demonstrate best practices. Such collaboration across diverse initiatives provides an experiment in governance (Sabel and Victor 2017; Cole 2015) and which will likely require reliable systems of review and assessment of both climate and non-climate outcomes. The transparency and compliance regimes of the Paris Agreement are minimally developed at this point. These regimes will be required to create methodologies to do things they have not done before (i.e., tracking progress on the fulfillment of policies under NDCs) and include groups of countries that have not had compliance responsibilities in the past.

\subsection{Launching and enhancing initiatives through linking to the UNFCCC}

The Paris Agreement starts to engage seriously with the realization that much present and future climate action will be driven by non-state actors (Chan et al 2016). In addition to specific language calling on non-state actors to increase their action and to states to engage with their non-state actors, several new UNFCCC institutions have been created to promote this engagement. This new orientation will provide significant benefits for the development and effectiveness of building blocks initiatives.

\subsubsection{Facilitating the development of new initiatives}

The non-climate incentives at the heart of building blocks initiatives are often more stable than climate altruism and can draw a limited number of actors into productive and durable initiatives. However, even where the incentives among a set of actors could be aligned, policy and institutional initiatives that operationalize such alignments may not occur. Policy entrepreneurs are key to the emergence of building blocks initiatives. These entrepreneurs can be individuals, NGOs, firms, or institutions that take the lead in understanding the opportunities for action; identifying and convening the appropriate actors; structuring the parameters of the initiative, including any institutional or legal arrangements; and ultimately launching the initiative. Across the wide breadth of existing initiatives, we have seen all manner of initiative entrepreneurs: the International Renewable Energy Agency in the development of the Island Lighthouses Initiative on renewables in small developing country islands; oil firms in the development of COSIA for the patent sharing arrangements; and the UNFCCC Conference of the Parties (COP) Presidencies of Lima, Paris, and Marrakech in the development of the initiatives that were announced at their COPs.

This process for creating initiatives is incredibly resource-intense. As a result, we have seen limited initiatives, even though there are significant opportunities for action. Support for policy entrepreneurs could be helpful in maximizing the development and uptake of opportunities. This support could be in the form of information on opportunities in areas of high mitigation potential, connecting and convening potential actors, sharing best practices on structuring initiatives, access to technical and financial resources, and providing a platform to gain visibility.

The UNFCCC, particularly after the Paris Agreement, may actually be one locus of support to create action outside of it. We know now that the UNFCCC will remain the central focus of international climate negotiations for at least the near term and that it has significant supportive resources (e.g., access to the Green Climate Fund, the Global Environment Facility, and the 
Adaptation Fund; know-how in project implementation and monitoring through the Clean Development Mechanism; and capacity building knowledge through the Durban Forum on Capacity Building), political participation and focus, and convening power. There are four aspects of the new agreement that may be helpful in launching new initiatives:

First, as we suggested earlier, enhanced NDCs may provide information on mitigation opportunities, sectoral gaps, and the political importance accorded to different types of mitigation. As we have said before, they provide a sort of "global shopping list" which entrepreneurs can structure building blocks. The Paris Agreement requires that countries bring forward new NDCs every 5 years. As this creates a regular system of NDC development (and is not seen by countries as a one-off thing), it is hoped that these INDCs would become an integrated part of a country's national planning process and would therefore contain more detailed and useful information than the initial set of NDCs.

Second, the Agreement creates a series of political moments (the 2018 Facilitated Dialogue and post-2020 Global Stocktake) intended to take stock of the "collective efforts" of the Parties and also have a role in "informing" the preparation of the NDCs. The dialogues should provide information on the aggregate uptake of mitigation activities and, importantly, the sectors in which there are unrealized opportunities.

Third, the successful Technical Expert Meetings (TEMs) initiated under Workstream 2 of the Durban Platform have been continued until at least 2020. The primary benefit of these meetings is to create, or uncover, knowledge about emissions reduction opportunities and their co-benefits - information necessary to structure building blocks - which, following Paris and Marrakesh, will now be more widely disseminated. A secondary benefit is the significant opportunities for regime entrepreneurs to participate in the relevant TEMs and, potentially, collaborate with the Secretariat and Technology Expert Committee in organizing the TEMs.

Fourth, the Paris COP Decision establishes two mechanisms that will encourage continuous high-event attention on new initiatives, including building blocks clubs and coalitions. Currently, a key factor limiting the development of initiatives has been the lack of continuous attention and pressure. The first mechanism created by the COP Decision is an annual highlevel event focused on near-term action that is to "provide an opportunity for announcing new or strengthened voluntary efforts, initiatives and coalitions." The second consists of two highlevel Champions appointed by the current and incoming COP Presidents to steer the high-level engagement and facilitate "the successful execution of existing efforts and the scaling-up coalitions."

\subsubsection{Enhancing the effectiveness of ongoing initiatives}

The Paris Agreement also contains provisions that can help strengthen initiatives that are already underway by linking them to the UNFCCC and helping to reduce the transaction costs of the initiative or by creating new financial incentives. There are two specific ways that the Agreement may be able to accomplish this. One concerns transparency and compliance; the other is the development of economic incentives for building blocks mitigation through internationally transferred mitigation outcomes (ITMOs).

Key components of many building blocks initiatives are transparency and compliance regimes. Without robust arrangements, it will be difficult to detect and deal with free riders, which may result in decreased benefit for the initiative participants and for the climate. However, developing such regimes is costly, and for potential initiatives in which 
the measurable benefits of participation are marginal, this may significantly inhibit their development. The Paris Agreement will establish new, potentially robust, and universal transparency and compliance regimes as a part of the work to bring the new Agreement into force. It is in the interest of countries, which have significant pressure to achieve their NDCs, to create a transparency regime that draws in mitigation methods from every possible emissions reduction, including those from non-state actors and transnational arrangements. Indeed, the NAZCA platform is already a proto-transparency system for non-state actors within the UNFCCC. To the extent that building blocks initiatives can use the UNFCCC regimes, it makes the transaction cost of starting new regimes that much more manageable.

The Paris Agreement also contains provisions concerning the use of markets and crediting mechanisms. As they are underdeveloped at this point, it is conceivable that the ITMOs, initially designed to be an authorization for linked emissions trading systems to be used for NDC fulfillment, could be broadened to provide a system of allocating the emissions reductions achieved through transnational building blocks action to the various participants in the initiative. Absent such authorization, it is unclear whether these reductions could be credited to individual countries accounts for NDC achievement, thus removing a beneficial incentive for state participation and support in building blocks. However, the ITMO regime should be allowed and encouraged to be developed in ways that provide a framework for reduction credit transfers between participants in building blocks initiatives that allows for flexibility and innovation.

\section{Conclusion}

Throughout this introduction, we have noted the ways in which building blocks initiatives have already been undertaken by a range of state and non-state actors. With the Paris Agreement's flexible architecture and mechanisms that can be used to increase the development of building blocks initiatives, we should expect that there will be an increased deployment of such initiatives and a corresponding increase in emissions reductions in addition to those created through the NDCs.

In this introduction, we have outlined the specific strategies to develop building blocks initiatives - clubs, linkage, and dominant actors - and shown the interactions between the strategies and with the Paris Agreement. In the articles in the Special Issue that follow, the excellent collection of authors expand and indeed enhance the concept of the building blocks initiatives. From them, we learn further about the benefits of starting small, in participants and subject matter; in correctly identifying the incentives for participation and corresponding costs that these incentives will bear; of experimenting and creating appropriate institutions that monitor progress; of not being too focused on theoretical distinctions; and of making bold proposals.

We hope that this is more than an academic exercise, that it creates a roadmap and a set of tools that can help inform, support, and influence the work of policy entrepreneurs in building new initiatives that reduce emissions.

Open Access This article is distributed under the terms of the Creative Commons Attribution 4.0 International License (http://creativecommons.org/licenses/by/4.0/), which permits unrestricted use, distribution, and reproduction in any medium, provided you give appropriate credit to the original author(s) and the source, provide a link to the Creative Commons license, and indicate if changes were made. 


\section{References}

Aldy JE (2017) Policy surveillance in the G-20 fossil fuel subsidies agreement: lessons for climate policy. Clim Change, pp 1-14

Aldy JE, Stavins RN (2007) Architectures for agreement: addressing global climate change in the post-Kyoto world. Cambridge University Press, Cambridge

Barrett S (2003) Environment and statecraft: the strategy of environmental treaty-making. Oxford University Press, Oxford

Benedick RE (1998) Ozone diplomacy: new directions in safeguarding the planet. Harvard University Press, Cambridge

Bodansky D (2016) The Paris Climate Change Agreement: a new hope? Am J Int Law 110(2):283-319

Bradford A (2013) The Brussels effect. Northwest U Law Rev 107:1-67

Buchanan JM (1965) An economic theory of clubs. Economica 32:1-14

Carin B, Mehlenbacher A (2010) Constituting global leadership: which countries need to be around the summit table for climate change and energy security? Glob Gov: Rev Multilateralism Int Organ 16:21-37

Chan S, Brandi C, Bauer S (2016) Aligning transnational climate action with international climate governance: the road from Paris. Rev Eur Comp Int Environ Law 25:238-247

Cole DH (2015) Advantages of a polycentric approach to climate change policy. Nat Clim Change 5:114-118

Falkner R (2016) A minilateral solution for global climate change? On bargaining efficiency, club benefits, and international legitimacy. Perspectives Politics 14:87-101

Green JF (2016) The world is about to get tough on aviation emissions. Here's what you need to know. Washington Post. https:/www.washingtonpost.com/news/monkey-cage/wp/2016/10/14/the-world-is-aboutto-get-tough-on-aviation-emissions-heres-what-you-need-to-know/. Accessed 26 Feb 2017

Green JF (2017) The strength of weakness: pseudo-clubs in the climate regime. Clim Change, pp 1-12

Hannam PM, Vasconcelos V, Levin SA, Pacheco JM (2017) Incomplete cooperation and co-benefits: deepening climate cooperation with a proliferation of small agreements. Clim Change, pp 1-15

Heal G, Kunreuther H (2017) Bottom-up climate policies. Clim Change

Keohane N, Petsonk A, Hanafi A (2017) Towards a club of carbon markets. Clim Change

Krugel L (2013) COSIA: Oil sands technology sharing making some progress, still much to do. Huffington Post Canada. http://www.huffingtonpost.ca/2013/11/26/cosia-oilsands-technology-sharing_n_4345674.html. Accessed 26 Feb 2017

Nordhaus WD (2015a) A new solution: the climate club. New York Rev Books 26:36-39

Nordhaus WD (2015b) Climate clubs: overcoming free-riding in international climate policy. Am Econ Rev 105: 1339-1370

Ovodenko A (2016) 140 countries will phase out HFCs. What are these and why do they matter? Washington Post. https:/www.washingtonpost.com/news/monkey-cage/wp/2016/11/03/140-countries-will-now-phaseout-hfcs-what-are-these-and-why-do-they-matter/. Accessed 26 Feb 2017

Potoski M (2017) Green clubs in building block climate change regimes. Clim Change, pp 1-11

Sabel CF, Victor DG (2017) Governing global problems under uncertainty: making bottom-up climate policy work. Clim Change, pp 1-13

Stewart RB, Oppenheimer M, Rudyk B (2013a) Building blocks for global climate protection. Stanford J Environ Law 33:341-392

Stewart RB, Oppenheimer M, Rudyk B (2013b) A new strategy for global climate protection. Clim Change 120: $1-12$

Stewart RB, Oppenheimer M, Rudyk B (2015) A building blocks strategy for global climate change. In: Barrett S, Carraro C, de Melo J (eds) Towards a workable and effective climate regime. Ferdi, Paris, pp 213-224

Tacconi L (2016) Preventing fires and haze in Southeast Asia. Nat Clim Change 6:640-643

UNFCCC (2015) Synthesis report on the aggregate effect of the intended nationally determined contributions. http://unfccc.int/resource/docs/2015/cop21/eng/07.pdf. Accessed 26 Feb 2017

Victor DG (2011) Global warming gridlock: creating more effective strategies for protecting the planet. Cambridge University Press, Cambridge

Vidal J (2016) Shipping 'progressives' call for industry carbon emission cuts. The Guardian. https://www. theguardian.com/environment/2016/oct/19/shipping-progressives-call-for-industry-carbon-emission-cuts. Accessed 26 Feb 2017

Wagner G, Kåberger T, Olai S, Oppenheimer M, Rittenhouse K, Sterner T (2015) Energy policy: push renewables to spur carbon pricing. Nature 525:27-29

Weischer L, Morgan J, Patel M (2012) Climate clubs: can small groups of countries make a big difference in addressing climate change? Rev Eur Commun Int Environ Law 21:177-192

WTO (2016) Progress made on Environmental Goods Agreement, setting stage for further talks. https://www. wto.org/english/news_e/news16_e/ega_04dec16_e.htm. Accessed 26 Feb 2017 